\title{
Rare Case of a Giant Left Atrium With Cerebrovascular Accident
}

\author{
Antoine El Khoury ${ }^{1}$, Marc Achkar ${ }^{2}$, Samer Nasr ${ }^{2}$ \\ 1. Cardiology, University of Balamand, Faculty of Medicine and Medical Sciences, Beirut, LBN 2. Cardiology, Mount \\ Lebanon Hospital, Beirut, LBN
}

Corresponding author: Antoine El Khoury, akhoury8@gmail.com

\begin{abstract}
Left atrium enlargement is very common in patients with valvular heart disease and atrial fibrillation but an extremely dilated left atrium is a very rare condition and rarely reported in the literature. It is a risk factor for ischemic cerebrovascular accidents due to blood stasis as the cavity diameter increases. We are reporting a case of rarely seen severely dilated left atrium with a normal functioning prosthetic mechanical mitral valve with a cerebrovascular accident on anti-vitamin $\mathrm{K}$ and aspirin. The patient had a left atrium diameter of $12.7 \mathrm{~cm}$, an area of $200 \mathrm{~cm}$ square, and a volume of $2000 \mathrm{cc}$. We elected to keep the international normalized ratio (INR) slightly above the therapeutic range in order to decrease the risk of ischemic events. It might be necessary to do the same for patients with a similar condition to decrease the stroke rates.
\end{abstract}

Categories: Cardiology, Neurology

Keywords: giant left atrium, atrial fibrillation, enlarged left atrium, mechanical valve, cerebrovascular accident, stroke

\section{Introduction}

The left atrium is an important structure in the heart, as it receives oxygenated blood from the lungs by the pulmonary veins and participates in left ventricular filling. When opposed to high afterload and high pressure or when the heart electrical activity is irregular in case of atrial fibrillation, the left atrium will increase in size to compensate for the high afterload [1]. This occurs in cases of diastolic dysfunction, hypertension, and valvular heart disease due to an increase in left ventricular pressure and is a risk factor for heart failure and cerebrovascular accidents [2-4].

Review began 04/17/2021 Review ended 04/24/2021 Published 04/26/2021

(c) Copyright 2021

El Khoury et al. This is an open access article distributed under the terms of the Creative Commons Attribution License CC-BY 4.0., which permits unrestricted use, distribution, and reproduction in any medium, provided the original author and source are credited.

\section{Case Presentation}

Our patient was a 60-year-old male with a history of long-standing hypertension, dyslipidemia, and permanent atrial fibrillation. He underwent mechanical mitral valve replacement 10 years ago with no major complications. His medications were bisoprolol, aspirin, warfarin, spironolactone, and furosemide. He presented for acute onset of slurred speech and right upper limb weakness associated with hypertension $(175 / 120 \mathrm{mmHg})$, with a heart rate of 75 beats per minute. ECG showed atrial fibrillation with normal ventricular rate and all laboratory tests were within normal range but he had a subtherapeutic international normalized ratio (INR) of 2.1. Chest X-ray showed massive cardiomegaly (Figure 1). 


\section{Cureus}

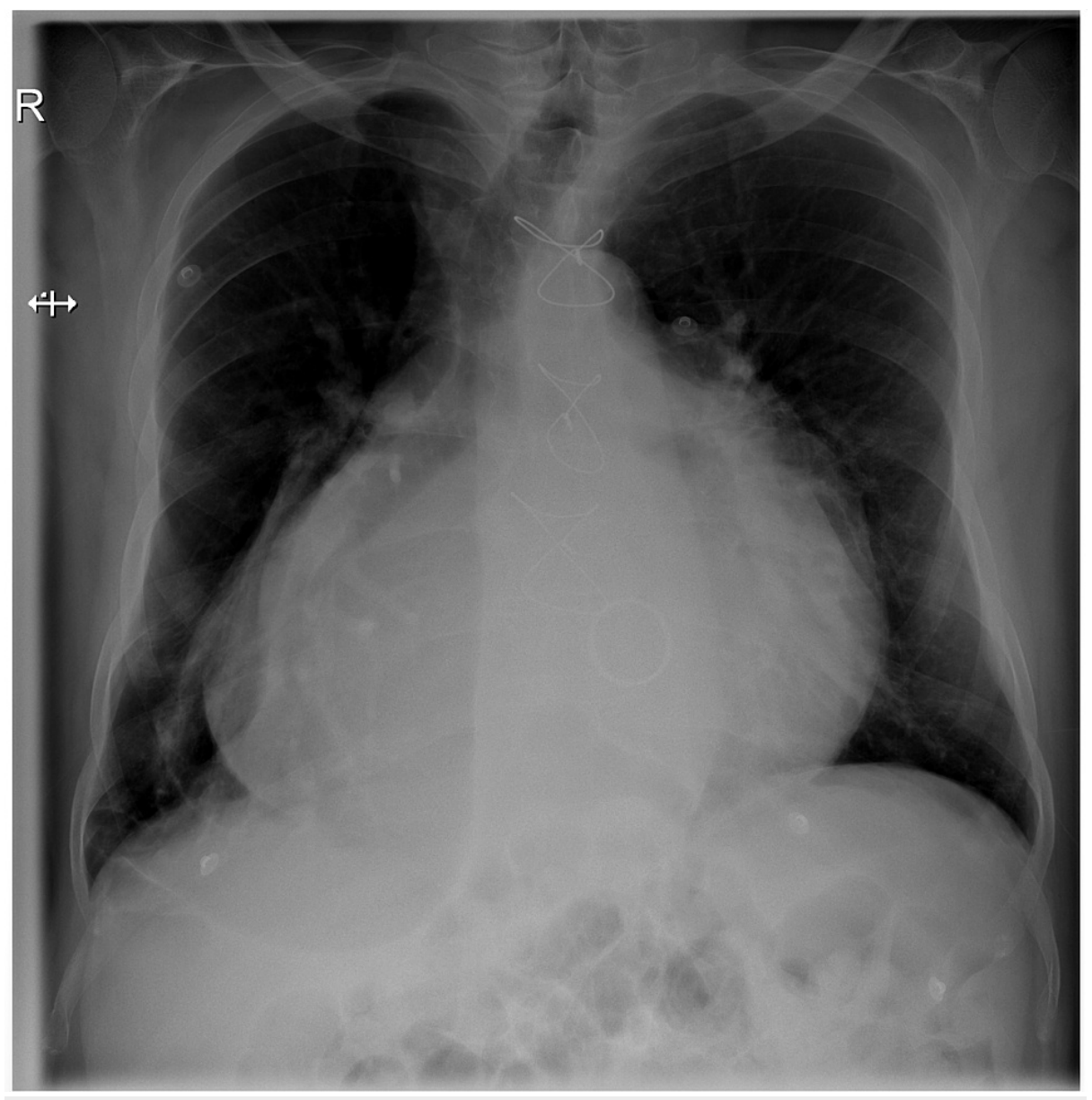

\section{FIGURE 1: Chest X-ray showing massive cardiomegaly}

An urgent CT of the brain was done and showed no acute hemorrhage but showed bilateral hypodensities within the pons, which were slightly edematous, likely related to subacute/chronic ischemic events. A $5 \mathrm{~mm}$ hyperdensity was also seen in the distal aspect of the basilar artery and raised the possibility of a small thrombus.

The patient was placed on enoxaparin and warfarin with a notable improvement of his symptoms in less than 24 hours and minimal residual weakness and slurred speech. He was scheduled for transthoracic echocardiography to assess his cardiomegaly and valve function and to look for a possible source of his brain embolic event. He had appropriate valve function but his left atrium was severely enlarged with a diameter of $12.4 \mathrm{~cm}$ and an area of $200 \mathrm{~cm}$ square and a volume of $2000 \mathrm{cc}$ (Figures 2-4). 


\section{Cureus}

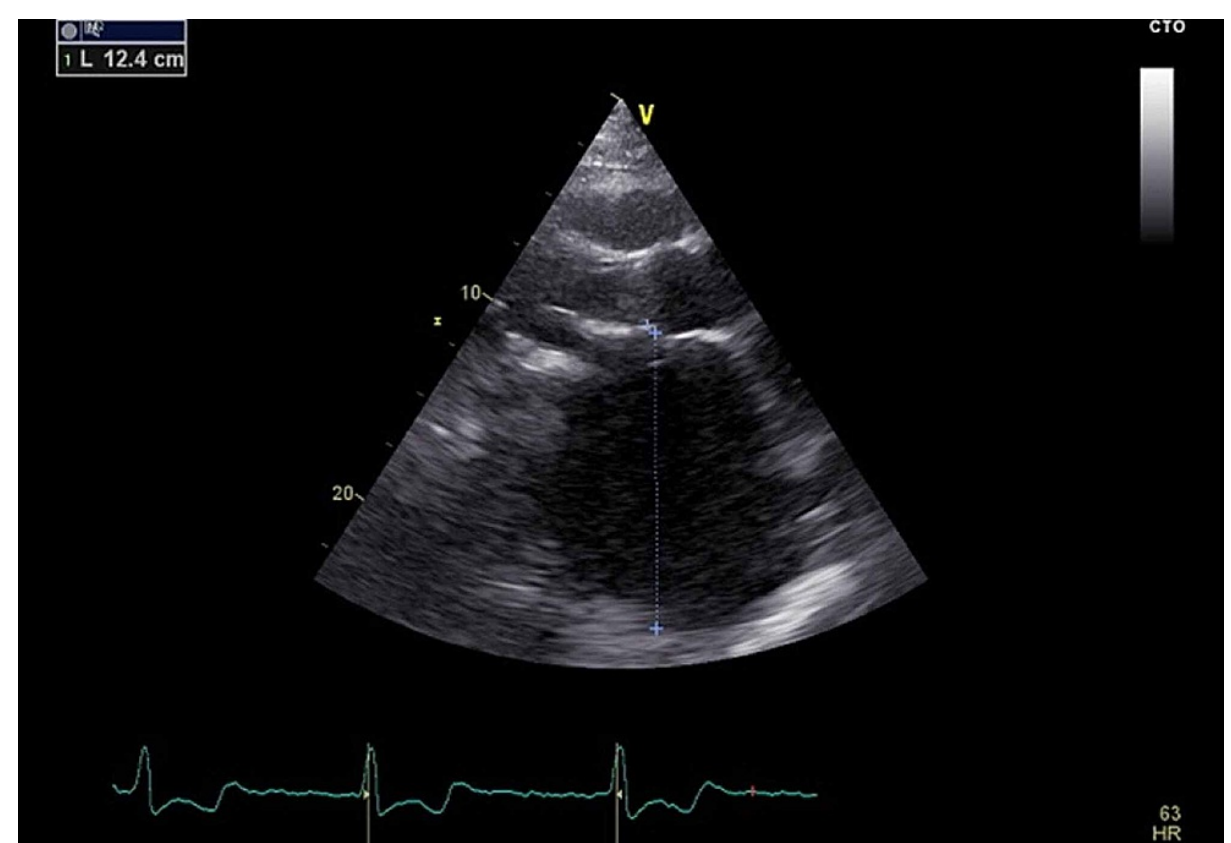

FIGURE 2: Echocardiography image of the left atrium (LA diameter) on the parasternal long-axis view

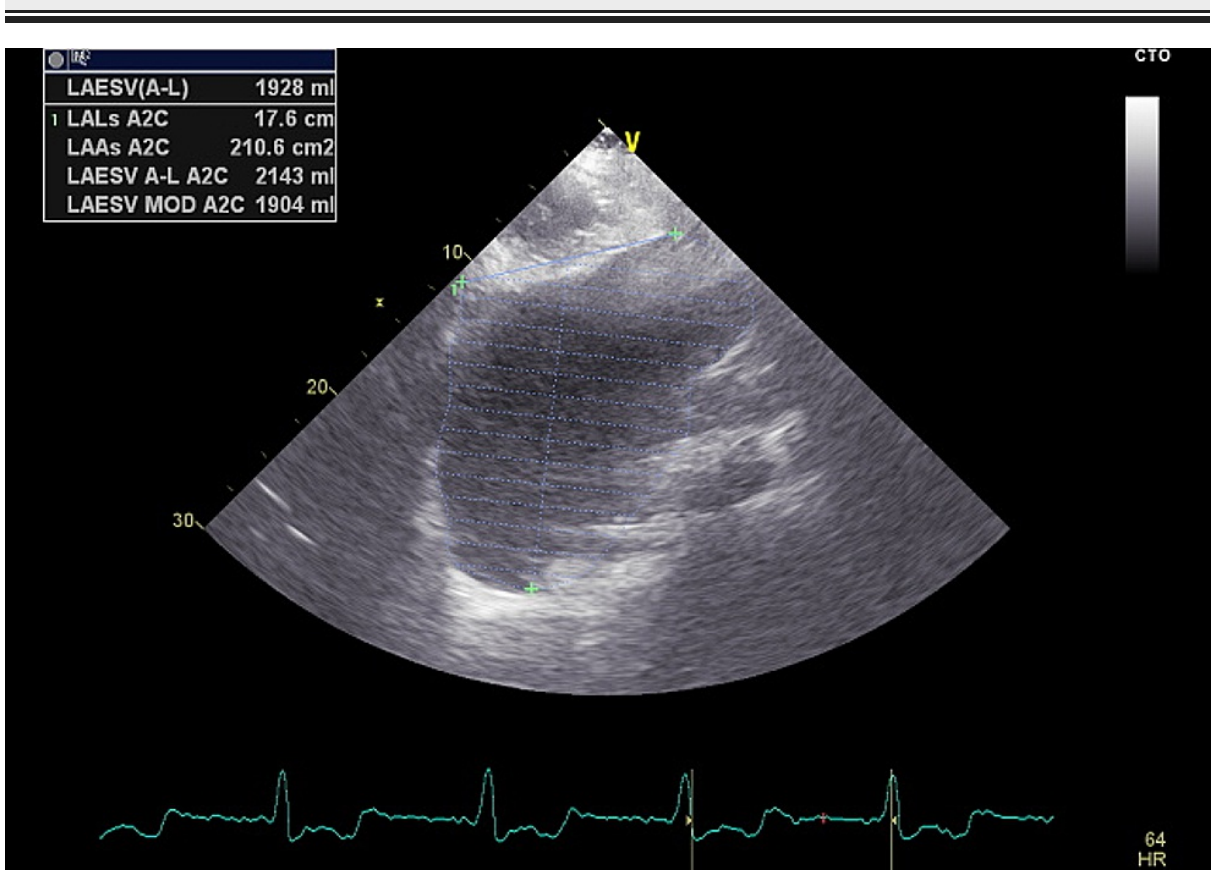

FIGURE 3: Echocardiography image of the left atrium (LA area) 


\section{Cureus}

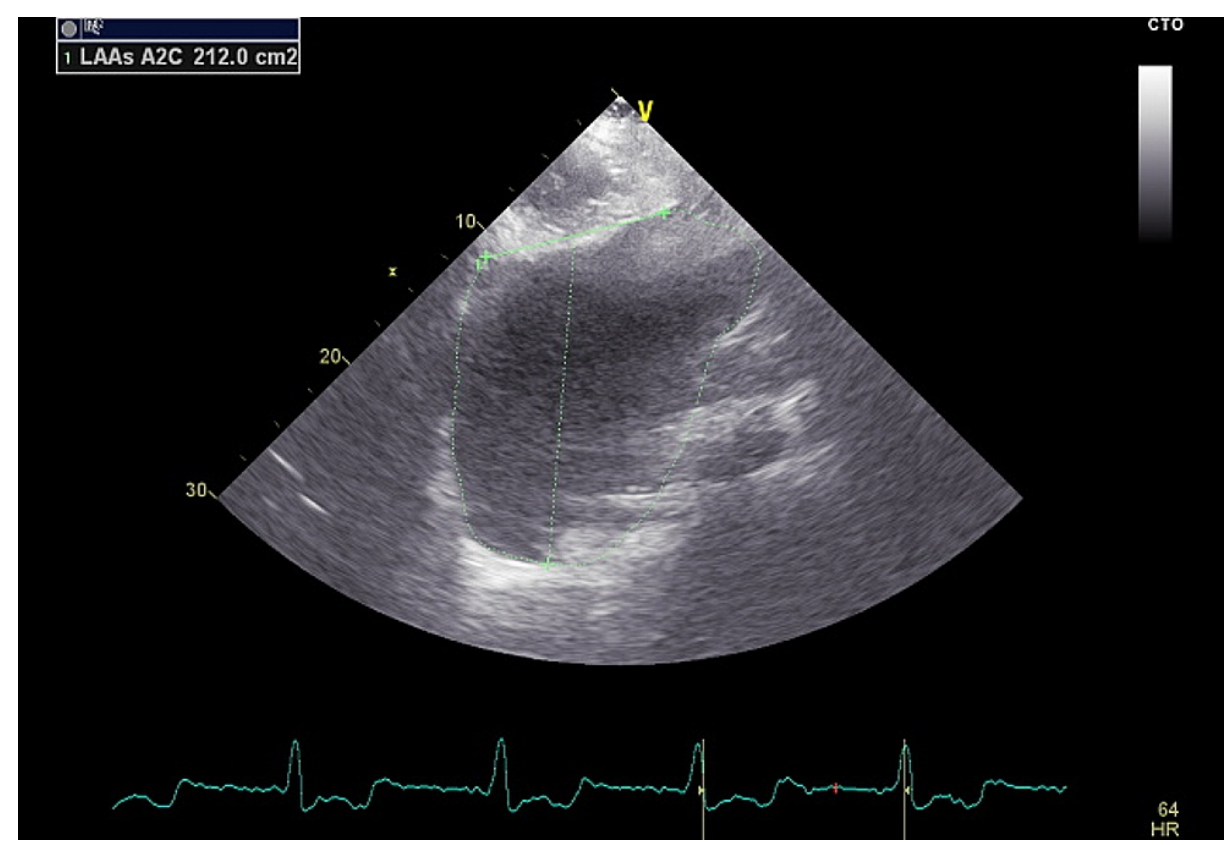

FIGURE 4: Echocardiography image of the left atrium (LA volume)

\section{Discussion}

According to the American Society of Echocardiography, left atrium enlargement can be classified as mild, moderate, or severe. Diameters of 4.1-4.6 cm in men or 3.9-4.2 cm in women are considered as mild enlargement, whereas diameters of 4.7-5.1 cm in men and 4.3-4.6 cm in women are classified as moderate and diameters of $\geqslant 5.2 \mathrm{~cm}$ in men or $\geqslant 4.7 \mathrm{~cm}$ in women as large [5]. The terminology of huge left atrium is for diameters larger than $6 \mathrm{~cm}$, and a left atrium with a diameter of more than $12 \mathrm{~cm}$ is very rarely reported in the literature. In addition to that, volumes above $2000 \mathrm{cc}$ are very uncommon [6]. The causes of left atrium enlargement include mitral stenosis or regurgitation, rheumatic valve, left ventricular failure, hypertension, left ventricular diastolic dysfunction, aortic stenosis, and atrial fibrillation [7-8].

The determination of left atrial size by echocardiography is an acceptable way of determining prognosis and cardiovascular outcomes such as heart failure and strokes due to the increased risk of thrombus formation [9]. Left atrial enlargement is associated with an increased risk of atrial fibrillation, which in turn increases the risk of cerebrovascular events and recurrent strokes [10]. This relation was found to be significant in both men and women as previous studies have shown $[5,11]$.

An enlarged left atrium is associated with a decreased ability of the heart to pump blood and is an independent risk factor for atrial fibrillation, and it was found that $19 \%$ of patients with an enlarged left atrial cavity had atrial fibrillation. Different studies showed that for every increase in LA diameter of more than $0.5 \mathrm{~mm}$, we had a $39 \%$ increase risk of atrial fibrillation [12]. Atrial fibrillation is also a risk factor for left atrial enlargement due to impaired ventricular filling and impaired cardiac output and can result in heart failure if chronic and uncontrolled [13]. Valvular dysfunction, mainly mitral valve diseases or impaired prosthetic mechanical mitral valve, was associated with big LA sizes, but note that huge left atrial diameters were also observed in patients with prosthetic valves that had normal function [14]. Atria of this size can cause compression of surrounding structures, leading to dysphagia by compressing the esophagus, hoarse voice by compressing the recurrent laryngeal nerve, and respiratory depression due to lung compression [14].

The patient we presented developed an ischemic brain event despite being on warfarin and aspirin. The giant left atrium size increases the risk of ischemic brain events. In that case, we aimed to keep the INR level slightly above the therapeutic range in order to avoid similar future events with more frequent INR followups. In addition, aspirin was replaced by clopidogrel because it was shown to be superior to aspirin in decreasing the risks for recurrent strokes [15]. Clopidogrel was also found to be superior to aspirin in reducing the risks for bleeding events [15]. In a different study, clopidogrel was found to be superior to aspirin in reducing gastrointestinal bleeding events only [16]. Clopidogrel and warfarin were continued together because it was shown that combining vitamin $\mathrm{K}$ antagonists (VKA) and antithrombotic therapy in patients with mechanical valves was superior to VKA alone [17-19]. There was a significant reduction in mortality rate and thromboembolism in the combination group with a moderate increase in bleeding events [17-18]. 


\section{Conclusions}

Our case illustrates a rarely seen left atrial size on a mechanically well-functioning valve with a cerebrovascular accident. The differential diagnosis on presentation can be misleading (pericardial effusion, mediastinal mass, or mechanical valve dysfunction ). We elected to keep the INR above 3.0 and replaced aspirin with clopidogrel to decrease the risk of gastrointestinal bleeding and ischemic brain events. The combination of VKA and antithrombotics was also shown to decrease the risk of ischemic events, with a moderate increase in bleeding events. It might be warranted to do the same in the future for patients with extremely large left atrial size prior to the occurrence of a cerebrovascular ischemic accident.

\section{Additional Information \\ Disclosures}

Human subjects: Consent was obtained or waived by all participants in this study. Conflicts of interest: In compliance with the ICMJE uniform disclosure form, all authors declare the following: Payment/services info: All authors have declared that no financial support was received from any organization for the submitted work. Financial relationships: All authors have declared that they have no financial relationships at present or within the previous three years with any organizations that might have an interest in the submitted work. Other relationships: All authors have declared that there are no other relationships or activities that could appear to have influenced the submitted work.

\section{References}

1. Keren G, Etzion T, Sherez J, Zelcer AA, Megidish R, Miller HI, Laniado S: Atrial fibrillation and atrial enlargement in patients with mitral stenosis. Am Heart J. 1987, 114:1146-1155. 10.1016/00028703(87)90190-6

2. Park SM, Park SW, Casaclang-Verzosa G, et al.: Diastolic dysfunction and left atrial enlargement as contributing factors to functional mitral regurgitation in dilated cardiomyopathy: data from the Acorn trial. Am Heart J. 2009, 157:762.e3-10. 10.1016/j.ahj.2008.12.018

3. Milan A, Puglisi E, Magnino C, et al.: Left atrial enlargement in essential hypertension: role in the assessment of subclinical hypertensive heart disease. Blood Press. 2012, 21:88-96. 10.3109/08037051.2011.617098

4. Maganti K, Rigolin VH, Sarano ME, Bonow RO: Valvular heart disease: diagnosis and management. Mayo Clin Proc. 2010, 85:483-500. 10.4065/mcp.2009.0706

5. Bouzas-Mosquera A, Broullón FJ, Álvarez-García N, et al.: Left atrial size and risk for all-cause mortality and ischemic stroke. CMAJ. 2011, 183:E657-64. 10.1503/cmaj.091688

6. Isomura T, Hisatomi K, Hirano A, Maruyama H, Kosuga K, Ohishi K: Left atrial plication and mitral valve replacement for giant left atrium accompanying mitral lesion. J Card Surg. 1993, 8:365-70. 10.1111/j.15408191.1993.tb00378.x

7. Rusinaru D, Bohbot Y, Kowalski C, Ringle A, Maréchaux S, Tribouilloy C: Left atrial volume and mortality in patients with aortic stenosis. J Am Heart Assoc. 2017, 6:e006615. 10.1161/JAHA.117.006615

8. Cuspidi C, Negri F, Sala C, Valerio C, Mancia G: Association of left atrial enlargement with left ventricular hypertrophy and diastolic dysfunction: a tissue Doppler study in echocardiographic practice. Blood Press. 2012, 21:24-30. 10.3109/08037051.2011.618262

9. Xu Y, Zhao L, Zhang L, Han Y, Wang P, Yu S: Left atrial enlargement and the risk of stroke: a meta-analysis of prospective cohort studies. Front Neurol. 2020, 11:26. 10.3389/fneur.2020.00026

10. Goldstein LB: Left atrial enlargement: a cause of stroke? . CMAJ. 2011, 183:1129-30. 10.1503/cmaj.110617

11. Benjamin EJ, D'Agostino RB, Belanger AJ, Wolf PA, Levy D: Left atrial size and the risk of stroke and death. The Framingham Heart Study. Circulation. 1995, 92:835-41. 10.1161/01.cir.92.4.835

12. Vaziri SM, Larson MG, Benjamin EJ, Levy D: Echocardiographic predictors of nonrheumatic atrial fibrillation. The Framingham Heart Study. Circulation. 1994, 89:724-30. 10.1161/01.cir.89.2.724

13. Lubitz SA, Benjamin EJ, Ellinor PT: Atrial fibrillation in congestive heart failure . Heart Fail Clin. 2010, 6:187-200. 10.1016/j.hfc.2009.11.001

14. Gajanana D, Morris DL, Janzer SF, George JC, Figueredo VM: Giant left atrium causing dysphagia. Tex Heart Inst J. 2016, 43:469-71. 10.14503/THIJ-15-5682

15. Paciaroni M, Ince B, Hu B, et al.: Benefits and risks of clopidogrel vs. aspirin monotherapy after recent ischemic stroke: a systematic review and meta-analysis. Cardiovasc Ther. 2019, 2019:1607181. 10.1155/2019/1607181

16. McQuaid KR, Laine L: Systematic review and meta-analysis of adverse events of low-dose aspirin and clopidogrel in randomized controlled trials. Am J Med. 2006, 119:624-38. 10.1016/j.amjmed.2005.10.039

17. Whitlock RP, Sun JC, Fremes SE, Rubens FD, Teoh KH: Antithrombotic and thrombolytic therapy for valvular disease. Antithrombotic Therapy and Prevention of Thrombosis, 9th ed: American College of Chest Physicians Evidence-Based Clinical Practice Guidelines. Chest. 2012, 141:e576S-600. 10.1378/chest.11-2305

18. Massel DR, Little SH: Antiplatelet and anticoagulation for patients with prosthetic heart valves . Cochrane Database Syst Rev. 2013, 2013:CD003464. 10.1002/14651858.CD003464.pub2

19. Little SH, Massel DR: Antiplatelet and anticoagulation for patients with prosthetic heart valves . Cochrane Database Syst Rev. 2003, 2003:CD003464. 10.1002/14651858.CD003464 